\title{
A sociopoética como facilitadora na expressão de clientes com autoimagem alterada por afecções dermatológicas
}

\author{
Sociopoetics as a facilitator in the expression of clients with \\ self-image altered by dermatological disorders
}

\author{
Patrícia Britto Ribeiro de Jesus' • Iraci dos Santos ${ }^{2}$
}

\begin{abstract}
RESUMO
Objetivo: analisar sob a perspectiva sociopoética como as pessoas acometidas por afecções dermatológicas, destacam os seus sentimentos quanto à autoimagem e à autoestima. Método: Estudo sociopoético que aborda o conhecimento do homem como ser político e social, além de ser prática de educar e cuidar.Após aprovação do Comitê de Ética em Pesquisa, os dados foram produzidos mediante a dinâmica do corpo como território mínimo (DCTM), utilizando um formulário, com questões inerentes à autoimagem alterada devido as afecções dermatológicas. Resultados: Os dados produzidos foram analisados conforme os estudos sociopoéticos transversal e classificatório. No transversal se destacam as categorias - Investindo no cuidado para o autocuidado e o desejo por uma pele íntegra x Imagem corporal elevada. No classificatório, a categoria percebendo e conhecendo a afecção dermatológica $x$ Descuidado consciente com o corpo. Os resultados permitiram responder à questão inicialmente formulada e alcançar os objetivos propostos. Sendo evidenciado através das categorias que a afecção dermatológica por acometer a roupagem do indivíduo implica em alterações no conforto, na imagem corporal, no convívio social, na autoimagem e autoestima, o compromete a qualidade de vida. Conclusão:A sociopoética como uma construção coletiva revelou-se como uma importante ferramenta tanto no cuidar/educar/pesquisar em enfermagem como na abordagem humanista aos clientes com afecções dermatológicas.Assim, este estudo contribuiu para uma ampliação da perspectiva da imagem e estima, na tentativa de possibilitar o desenvolvimento do cuidado de enfermagem cada vez mais próximo ao cliente por meio da interação e do diálogo. Descritores: Enfermagem; Dermatologia;Autoimagem;Autoestima.
\end{abstract}

\begin{abstract}
Objective: to analyze from a sociopoetic perspective how people affected by dermatological disorders highlight their feelings about self-image and self-esteem. Method:A sociopoetic study that addresses man's knowledge as a political and social being, in addition to being a practice of educating and caring.After approval by the Research Ethics Committee, the data were produced using the dynamics of the body as a minimum territory (DCTM), using a form, with issues inherent to the altered self-image due to dermatological conditions. Results:The data produced were analyzed according to cross-sectional and classificatory sociopoetic studies. In the cross section, the categories stand out - Investing in care for self-care and the desire for a healthy skin $\mathrm{x}$ High body image. In the classification, the category perceiving and knowing the dermatological condition $x$ Careless conscious with the body. The results made it possible to answer the question initially formulated and achieve the proposed objectives. Being evidenced through the categories that the dermatological affection for affecting the individual's clothes implies changes in comfort, body image, social life, self-image, and self-esteem, compromising the quality of life. Conclusion:Sociopoetics as a collective construction has revealed itself as an important tool both in caring / educating / researching in nursing and in the humanistic approach to clients with dermatological disorders. Therefore, this study contributed to an expansion of the perspective of image and esteem, to enable the development of nursing care ever closer to the client through interaction and dialogue.

Descriptors: Nursing; Dermatology; Self image; Self esteem.
\end{abstract}

I Professora Assistente do Departamento de Fundamentos de Enfermagem da Faculdade de Enfermagem da UERJ. Professora no Curso de Graduação em Enfermagem e no Curso de Pós-Graduação Lato-Sensu de Enfermagem em Dermatologia do Centro Universitário Celso Lisboa. Experiência na área de Enfermagem, atuando principalmente nos seguintes temas: Fundamentos de Enfermagem, Clínica Médica, cuidados as pessoas com estomas e afecções cutâneas. E-mail: patty_brj@hotmail.com. Link currículo lattes: http://lattes.cnpq.br/768I0525 I94II27I

2 Livre-Docente em Pesquisa em Enfermagem pela Universidade do Estado do Rio de Janeiro. Professora Titular de Pesquisa em Enfermagem pela Universidade do Estado do Rio de Janeiro. Pós-doutorado em Filosofia da Ciência na Universidade Federal de Santa Catarina. Experiência na área de Enfermagem, com ênfase em Fundamentos de Enfermagem, Administração em Enfermagem e Pesquisa em Enfermagem. E-mailiraci.s@terra.com.br. Link currículo lattes: http://lattes.cnpq. $\mathrm{br} / 1318743593194994$ 


\section{INTRODUÇÃO}

$\mathrm{Na}$ área de saúde, o cuidado de enfermagem dispensado ao cliente reflete como o profissional o percebe, assim como sua visão sobre a prática de atendimento à pessoa. Tais considerações levam ao crédito de que, o cuidar de enfermagem em dermatologia requer dos profissionais habilidades sociais referentes à: saber ouvir, compreender, aconselhar e tentar realizar um trabalho de autoconhecimento, visando, principalmente, reconstituir as relações sociais que estejam abaladas.

Considerando que a enfermeira tem uma relação direta com o cuidar/ cuidado, ao lidar e potencialmente identificar as lesões cutâneas mais frequentes que acometem os pacientes hospitalizados, levará esse profissional a planejar, organizar, implementar e avaliar as ações do cuidado prestado às pessoas com lesões agudas e crônicas, objetivando minimizar o tempo de internação e a consequente diminuição dos custos por internações prolongadas ${ }^{(1)}$.

Desse modo, na perspectiva sociopoética emerge a força instituinte do corpo quando é dado valor e respeito a sua existência no contexto hospitalar. Esse fenômeno promove uma relação isonômica, horizontal, atentiva, compreensiva da cultura, costumes, padrões e hábitos

diários das pessoas ${ }^{(2)}$. Tal horizonte poderá contribuir, de forma significativa, na possibilidade de investigação dos aspectos intrínsecos a pessoa e à profissão tais como a solicitude, a sensibilidade, a relação terapêutica e a educação terapêutica.

A sociopoética é entendida como uma prática social, de cuidar, de educar e de pesquisa. Foi criada no Brasil, na década de 90 , pelo filósofo e pedagogo francês Jacques Gauthier. $O$ corpo pensado à luz da sociopoética de forma teórica e metodológica, por si fala e fornece suporte à subjetividade humana para que se materialize no momento de desequilíbrio, não somente físico, mas emocional e espiritual inclusive. Ao exercer seu ofício e utilizar o corpo como instrumento, o enfermeiro deve possuir o interesse de atingir o eco sensível e necessário ao cuidado de enfermagem, seja ele completo e de interesse para a saúde das pessoas que ele cuida. ${ }^{(2)}$.

A Sociopoética surgiu do encontro entre a Pedagogia do oprimido de Paulo Freire ${ }^{(3)}$, a Análise institucional de René Lourau ${ }^{(4)}$, a Esquizo análise de Deleuze e Guattari ${ }^{(5)}$, a Escuta mitopoética de René Barbier ${ }^{(6)}$ e o Teatro do oprimido de Augusto Boal( ${ }^{(7)}$.

Refletindo sobre a sociopoética como uma prática de cuidar quanto à singularidade do ser humano para reagir, aprender e se adaptar na sua convivência no mundo, consigo e com os outros, assim como a sua dimensão imaginativa, indaga-se a seguinte questão norteadora: quais são as repercussões do acometimento cutâneo na vida das pessoas?
Teve-se como objetivo: analisar sob a perspectiva sociopoética como as pessoas acometidas por afecções dermatológicas, destacam os seus sentimentos quanto à autoimagem e à autoestima.

\section{MÉTODO}

Trata-se de um estudo sociopoético. Os participantes foram 18 clientes com afecções dermatológicas hospitalizados que desenvolveram a dinâmica do corpo como território mínimo oriunda do estudo sociopoético no período de maio a agosto de 2013.

Como critérios de inclusão: aqueles com afecções próprias da clínica de dermatologia, e que atenderam aos critérios de: locomoção própria e expressão verbal indispensáveis ao desenvolvimento das técnicas de pesquisa, e que concordaram em participar dessa investigação, assinando o Termo de Consentimento Livre e Esclarecido (TCLE). Os critérios de exclusão foram: os que se encontravam com lesões extensas, e, portanto, impossibilitados de participarem de oficinas sociopoética, que exigem dinâmicas de sensibilidade dependentes de movimentação do corpo, exercícios respiratórios e outros. Na sociopoética, os participantes da pesquisa são denominados como Grupo Pesquisador (GP).

Essa denominação foi necessária pois ao se tomar conhecimento de pesquisas envolvendo a arte e baseadas na sociopoética, que aconteciam de forma mais proveitosas e mais lúdicas, mais prazerosas, mas sem que o grupo pesquisado tome poder algum na produção do conhecimento, a formação do assim chamado "grupo-pesquisador", autor coletivo da pesquisa, responsável pelo seu desenvolvimento e "dono" do conhecimento produzido(9).

O local de estudo ocorreu no Hospital Universitário localizado na cidade do Rio de Janeiro. O local escolhido para a realização das dinâmicas foi no Anfiteatro de Dermatologia localizado ao lado da Enfermaria de Dermatologia, no segundo andar, porém este local dispõe de cadeiras fixas no chão e televisão de plasma para projeção de slides. Sendo possível apenas realizar a primeira oficina sociopoética, visto que as demais prescindem de espaço para mobilização dos sujeitos de pesquisa no desenvolvimento de dinâmicas de relaxamento e de sensibilidade, incentivadoras do imaginário. Diante dessa dificuldade utilizou-se a varanda da própria enfermaria, onde os clientes estavam internados.

Para a produção de dados selecionou-se a técnica de pesquisa Dinâmica do Corpo como Território Mínimo (DCTM). Por meio do encontro sociopoético com uso de duas dinâmicas próprias, incitam no grupo uma postura dialógica ao revelarem a potência da criatividade e sensibilidade ${ }^{(10)}$.

A DCTM tem a propriedade como uma técnica de produção de dados dentro da sociopoética favorece o 
conhecimento inconsciente, que está na pele, impresso no corpo - e que muitas vezes traz em si os sentidos mais genuínos daquilo que se viveu - é mais facilmente acessado por meio da linguagem não verbal e de expressões artísticas. ${ }^{(11)}$.

Acerca da DCTM, as pesquisadoras seguiram os seguintes passos:

A. Para o incentivo do imaginário, diminui-se a iluminação ambiental e solicitou-se ao GP, que se concentrasse na música tentando refletir sobre o que havíamos falado anteriormente em relação à autoimagem, à autoestima, às mudanças ocorridas na vida devido ao acometimento cutâneo.

B. Então, as pesquisadoras apresentaram o tema orientador da pesquisa - a autoimagem e autoestima de pessoas com afecções dermatológicas, o qual foi aceito pelo GP, iniciando-se um diálogo e tempestade cerebral sobre este.

C. Diálogo com o GP sobre o entendimento da palavra território para que, posteriormente, haja consenso em torno da ideia de que nosso corpo possa ser concebido como nosso território mínimo.

D. Solicitação aos membros do GP, para imaginar como percebem e apreciam seu corpo e após isso responderem as perguntas contidas no formulário.

E. Preenchimento do formulário com as seguintes perguntas: como eu me vejo? Como você se sente em relação ao seu autocuidado? Como eu gostaria de me ver e de ser cuidado?

Os participantes de pesquisa, nesse momento de expressão, têm a liberdade para fugir um pouco daquilo que tradicionalmente executam/vivenciam no dia a dia. Após isso houve verbalização dos membros do GP sobre o que gostam e o que não gostam e como cuidam deste seu território.

Quanto aos procedimentos de análise e tratamento dos dados qualitativos os mesmos foram produzidos, através da dinâmica do corpo como território mínimo foram tratados pela análise categorial específica da sociopoética. Os depoimentos resultantes da dinâmica do corpo como território mínimo foram transcritos na íntegra para a realização da análise. A partir de então, foi elaborado quadros demonstrativos com os principais temas individuais apresentados pelos participantes. Nessa fase, o pesquisador retorna ao grupo com os resultados de sua análise individual, com uma exposição visual em slides dos quadros demonstrativos, e este assim o grupo pode avaliá-la. É importante um momento dialogal para possibilitar uma integração de ideias e oposições.

As questões éticas seguiram as recomendações da
Resolução $n^{\circ}$ 466/ 12 do Conselho Nacional de Saúde do Ministério da Saúde. O projeto de pesquisa foi aprovado pelo Comitê de Ética em Pesquisa do Hospital Universitário Pedro Ernesto da Universidade do Estado do Rio de Janeiro (CAAE I06834I2.2.0000.5259).

\section{RESULTADOS E DISCUSSÃO}

Conforme a tendência das respostas na DCTM foi realizado um quadro demonstrativo com as questões orientadoras (categorias teóricas) e contexto das falas dos sujeitos (categorias empíricas). Após a realização do quadro demonstrativo e leitura das categorias empíricas, surgiram os temas individuais segundo as questões orientadoras correspondentes.

No Quadro I, são descritos os temas individuais que apareceram com maior frequência nas categorias empíricas diante da análise das falas dos sujeitos de pesquisa, e assim como a similaridade dos temas para a formação das categorias temáticas.

As categorias temáticas emergiram diante da frequência dos temas individuais do GP, conforme se observa no Quadro 2.

Foi possível delimitar 28 temas individuais os quais foram subdivididos por sete categorias analíticas, tais como: I) Disposição para autocuidado melhorado composta por cinco temas; 2) Descuidado consciente com o corpo composta por dois temas;3) Percebendo e conhecendo a afecção dermatológica composta por quatro temas; 4) Cuidado composta por dois temas; 5) Imagem corporal elevada composta por 05 temas; 6) O desejo por uma pele íntegra composta por dois temas; 7) Comprometimento da autoimagem frente às repercussões da afecção dermatológica composta por oito temas (Figura I).

Analisando os dados produzidos através da técnica da DCTM com destaque para os temas individuais e a delimitação das categorias analíticas deles decorrentes, notou-se a propriedade da escolha dos estudos sociopoéticos transversal e classificatório, que serão descritos respectivamente. $O$ primeiro estudo revela as ligações entre coisas aparentemente diferentes que surgem na produção das oficinas de pesquisa. $O$ segundo estudo enfoca nos dados produzidos as oposições existentes no conjunto das produções do GP ${ }^{(12)}$.

Portanto, para atingir o objetivo proposto pela pesquisa, a análise dos dados foi constituída de três categorias: investindo no cuidado para o autocuidado: estudo transversal; o desejo por uma pele íntegra $x$ Imagem corporal elevada: estudo transversal; percebendo e conhecendo a afecção dermatológica $\times$ Descuidado consciente com o corpo: estudo classificatório. As categorias estão expostas a seguir descrevendo os principais resultados da pesquisa. 
QUADRO 1 - Temas individuais da dinâmica do corpo como território mínimo. Rio de Janeiro, RJ, Brasil, 2013

\begin{tabular}{|c|c|c|}
\hline Questões Orientadoras & Temas individuais & Frequência dos temas \\
\hline \multirow{14}{*}{ Como eu me vejo? } & Feliz pela descoberta do diagnóstico & 1 \\
\hline & Vivendo melhor após saber como e porque precisa se cuidar & 2 \\
\hline & A doença não atrapalha na forma como se vê & 2 \\
\hline & Mantêm equilíbrio emocional & 1 \\
\hline & Estigma da doença & 3 \\
\hline & Baixa autoestima & 3 \\
\hline & Vergonha de si mesmo & 1 \\
\hline & Percepção da doença & 3 \\
\hline & Superação da doença & 1 \\
\hline & Pessoa normal x Pessoa com doença de pele & 1 \\
\hline & Limitação da doença & 1 \\
\hline & Imagem corporal prejudicada & 1 \\
\hline & Negação da doença & 1 \\
\hline & Isolamento do corpo & 1 \\
\hline \multirow{5}{*}{$\begin{array}{l}\text { Como você se sente em relação ao } \\
\text { seu autocuidado? }\end{array}$} & Melhora do autocuidado após descoberta da doença & 2 \\
\hline & Satisfeito com meu autocuidado & 6 \\
\hline & Descuido com o corpo & 3 \\
\hline & Autocuidado somente em relação às lesões na pele & 1 \\
\hline & Descuido quanto à doença & 1 \\
\hline \multirow{9}{*}{$\begin{array}{l}\text { Como eu gostaria de me ver e de } \\
\text { ser cuidado? }\end{array}$} & Gostaria de ter minha pele íntegra. & 6 \\
\hline & Agradecido pelo cuidado recebido & 2 \\
\hline & Normal & 1 \\
\hline & Ser livre da doença & 3 \\
\hline & Cuida-se por si só & 1 \\
\hline & Elevação da autoestima & 1 \\
\hline & Espiritualidade/Religiosidade & 1 \\
\hline & Persistência no cuidado & 3 \\
\hline & Gostaria de ser atendido com respeito à minha fragilidade e humanidade. & 4 \\
\hline
\end{tabular}

QUADRO 2 - Categorias e temas individuais do GP na DCTM. Rio de Janeiro, RJ, Brasil, 2013

\begin{tabular}{|c|c|}
\hline Categorias Temáticas & Temas individuais \\
\hline Disposição para autocuidado melhorado & $\begin{array}{l}\text { Satisfeito com meu autocuidado } \\
\text { Persistência no cuidado } \\
\text { Melhora do autocuidado após descoberta da doença } \\
\text { Cuida-se por si só } \\
\text { Autocuidado somente em relação às lesões na pele }\end{array}$ \\
\hline Cuidado & $\begin{array}{l}\text { Gostaria de ser atendido com respeito à minha fragilidade e } \\
\text { humanidade. } \\
\text { Agradecido pelo cuidado recebido }\end{array}$ \\
\hline O desejo por uma pele íntegra & $\begin{array}{l}\text { Gostaria de ter minha pele íntegra } \\
\text { Ser livre da doença }\end{array}$ \\
\hline Percebendo e conhecendo a afecção dermatológica & $\begin{array}{l}\text { Vivendo melhor após saber como e porque precisa se cuidar } \\
\text { Percepção da doença } \\
\text { Elevação da autoestima } \\
\text { Espiritualidade/religiosidade }\end{array}$ \\
\hline Imagem corporal elevada & $\begin{array}{l}\text { Feliz pela descoberta do diagnóstico } \\
\text { A doença não atrapalha na forma como se vê } \\
\text { Mantêm equilíbrio emocional } \\
\text { Superação da doença } \\
\text { Normal }\end{array}$ \\
\hline $\begin{array}{l}\text { Comprometimento da autoimagem frente às repercussões da } \\
\text { afecção dermatológica }\end{array}$ & $\begin{array}{l}\text { Pessoa normal x Pessoa com doença de pele } \\
\text { Limitação da doença } \\
\text { Autoimagem comprometida } \\
\text { Negação da doença } \\
\text { Isolamento do corpo } \\
\text { Estigma da doença } \\
\text { Baixa autoestima } \\
\text { Imagem corporal prejudicada }\end{array}$ \\
\hline Descuidado consciente com o corpo & $\begin{array}{l}\text { Descuido com o corpo } \\
\text { Descuido quanto à doença }\end{array}$ \\
\hline
\end{tabular}




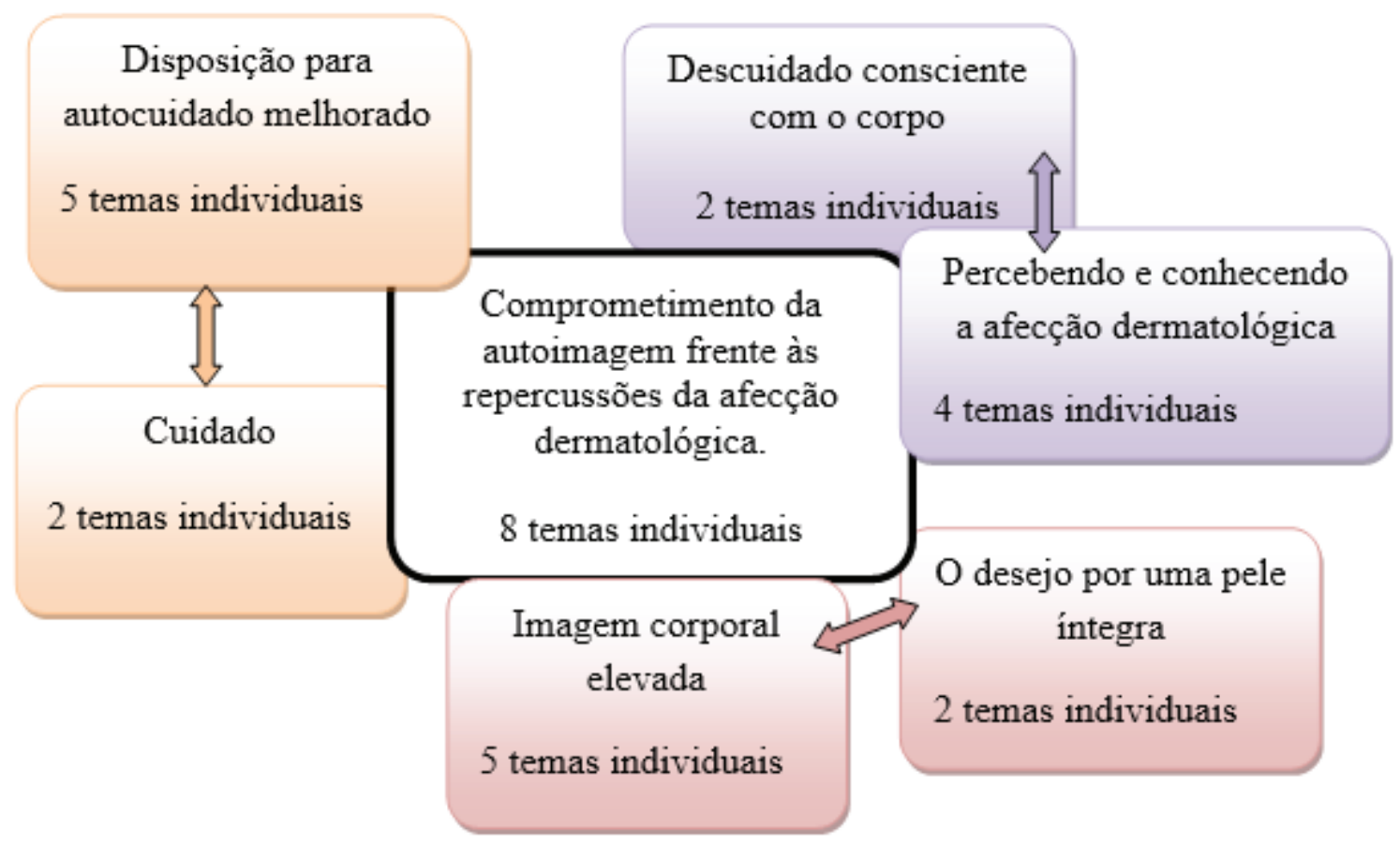

FIGURA 1 - Diagrama dos componentes da análise categorial da DCTM. Rio de Janeiro, RJ, Brasil, 2013. Fonte: Pesquisa direta.

Categoria I. Investindo no cuidado para o autocuidado: estudo transversal

No primeiro estudo sociopoético do tipo transversal referente a descrição de investindo no cuidado para o autocuidado, foi composto por duas categorias: Cuidado e Disposição para autocuidado melhorado. A primeira emergiu dos temas individuais que revelam a estrutura de pensamento de cada membro do grupo-pesquisador, a saber: gostaria de ser atendido com respeito à minha fragilidade e humanidade; e agradecido pelo cuidado recebido. Analisando tais temas percebeu-se a urgência de pensar em uma modalidade de cuidado que possa ver e compreender o cliente como um ser integral, cujos aspectos sociais, psicológicos, mentais, espirituais e ambientais do seu viver possam ser considerados no contexto do seu atendimento na área de saúde.

Nessa perspectiva, a enfermagem, uma profissão científica e humanística, que é apreendida e focada no fenômeno do cuidado humano e em atividades que propiciem assistência e suporte, no sentido de manter ou rever seu bem-estar (13), conforme se observa nas falas dos membros do GP:

Gostaria de receber um cuidado sem pressa, com atenção e com responsabilidade e carinho. Aqui eu sempre fui bem cuidada, não tenho o que reclamar, elas me dão uma atenção legal. $E$ de ser tratada com carinho, pois tenho me sentido frágil em certos momentos. (Grupo-Pesquisador)

Esse apoio social e atenção fazem parte do cuidar da equipe de enfermagem que trabalha diariamente e diuturnamente com esses clientes nas unidades de internação, tem a possibilidade de estar junto, visando identificar suas necessidades humanas e desejos.

Por isso, afirma-se a que a sociopoética como método de pesquisa avança para a prática de cuidar e educar haja vista nesta investigação junto aos clientes com afecções dermatológicas, onde proporcionou um diálogo da pesquisadora para com os copesquisadores ${ }^{(14)}$.

Ressaltando-se assim que os profissionais da saúde que prestam os cuidados, além do conhecimento científico e capacidade técnica necessária na prestação do cuidado integral, necessitam ter características essenciais para a profissão como afetividade, amorosidade e conhecimento ${ }^{(15)}$.

Ao escutar o outro em suas necessidades e desejos, a sociopoética convida para o cuidado estético que pode ser considerado como aquele que considera, no serl cliente, a sua condição humana ${ }^{(16)}$, observando sob essa perspectiva que a enfermeira demonstra o seu cuidado subjetivo que ultrapassa o fazer prático.

\section{Categoria 2. O desejo por uma pele íntegra $x$} Imagem corporal elevada: estudo transversal

A segunda categoria emergiu da correlação: o desejo por uma pele íntegra e satisfação com o próprio corpo. A primeira compõe-se dos temas individuais: gostaria de ter minha pele íntegra; e ser livre da doença. A segunda foi formada pelos seguintes temas individuais, a saber, a doença não atrapalha na forma como se vê; mantêm 
equilíbrio emocional; sem percepção da enfermidade; superação da doença; agradece a Deus pela cura e feliz pela descoberta do diagnóstico.

Exemplificando a categoria desejo por uma pele íntegra apresenta-se a fala dos copesquisadores:

No momento me vejo limitada para fazer todas as minhas tarefas. Quanto ao meu corpo, procuro não olhar no espelho. [...] antes tinha vergonha de mim devido às marcas, cicatrizes e machucados, hoje tenho vergonha sim das marcas, mas principalmente das pessoas que são preconceituosas. Gostaria de voltar ao que era há cinco anos, antes da doença 58 $\mathrm{kg}$, manequim 38, cabelos bem cuidados, isso já com três filhos... Gostaria de me ver curada. (Grupo-Pesquisador)

Como em qualquer doença, o desejo de não a ter em seu corpo é mais do que evidente, porém sendo uma doença dermatológica, a mesma fica visível e impressa na pele tanto para a pessoa acometida quanto para os outros. A nossa pele reflete tanto para o mundo externo como para o mundo interno levando assim a repercussões variadas em sua vida ${ }^{(17)}$.

Notando-se assim um grande desafio para os sujeitos, pois a adaptação a uma doença dermatológica pode provocar profundas alterações na autoimagem, fazendo com que o indivíduo, muitas vezes, vivencie sentimentos como tristeza e angústia, que pode se intensificar ainda mais, dependendo do tipo de estímulo que recebe das pessoas de seu ciclo social, onde sua percepção de autoimagem pode se tornar mais comprometida. ${ }^{(18)}$

Destaca-se no relato dos copesquisadores, a palavra cura, gostaria de se ver sem a doença levando uma vida normal. Porém, o maior número de casos nesse estudo se refere à Psoríase. A Psoríase é caracterizada como uma doença autoimune da pele, multifatorial, ou seja, é de herança poligênica e evolução crônica ${ }^{(19)}$.

Portanto, alguns eventos indutores de estresse e/ou traumáticos podem contribuir para o aparecimento e/ou agravamento da doença, assim como os seguintes fatores ambientes e outros como clima, luz, drogas; traumas e microtraumatismos cutâneos quer físicos, químicos, elétricos ou cirúrgicos; infecções causadas pelo vírus da imunodeficiência humana (HIV) e pelo estreptococo; alterações metabólicas e endócrinas como diabetes, tireoidopatias e hipocalcemia; o fumo e o álcool, além dos fatores psicogênicos (psoríase latente) ${ }^{(19)}$.

Exemplificando o conteúdo da categoria - Satisfação com o próprio corpo, descreve-se as seguintes falas do GP: Normal, não afetou em nada particularmente. Como uma música que tenta acalmar a minha mente. Sinto-me bem, me cuido da higienização das minhas feridas, procuro administrar meus remédios nos horários corretos. Me vejo como uma pessoa comum, mas tem umas pessoas que tem preconceito... (Grupo-Pesquisador)

Diante disso, percebeu-se que apesar do caráter crônico e estigmatizante da doença dermatológica, alguns membros do grupo-pesquisador buscam em si tanto superar a doença como aprender a conviver com ela. Isso foi possível, convivendo no sentido de saber lidar com as lesões e complicações decorrentes da doença assim como manejar as questões emocionais e psicológicas frente ao contexto em que se vive.

Tal situação decorre da personalidade, dos costumes, dos valores que a pessoa tem e como ela percebe seu próprio corpo. Contudo, a percepção do indivíduo encontra-se investida para o exterior condicionada a realidade coletiva, ou seja, a satisfação do indivíduo está dependente das normas sociais. Portanto, uma pessoa é capaz de distinguir as emoções que sente acerca de si mesma, sejam elas favoráveis ou não, sendo estas consequências do olhar que a pessoa lança sobre si própria e do diálogo que trava com si mesma ${ }^{(20)}$.

Assim, no grupo pesquisador foi possível perceber que muitos lançam um olhar positivo sobre sua afecção, que apesar de sua existência não comprometem a sua vida diária e nem seus sentimentos. Nesse sentido, o indivíduo como um ser livre, é aquele que escolhe ser e também perceber o encontro de sua existência ao se estabelecer o conhecimento de si, mediante a busca de compreensões e descobertas, efetivando seu posicionamento no mundo de maneira consciente e responsável as escolhas assumidas ${ }^{(21)}$.

Categoria 3. Percebendo e conhecendo a afecção dermatológica $x$ Descuidado consciente com o corpo: estudo classificatório

O estudo foi composto utilizando a delimitação das categorias: percebendo e conhecendo a afecção dermatológica e o descuidado consciente com o corpo. A primeira, foi formada por dois temas individuais a saber: vivendo melhor após saber como e porque precisa se cuidar; percepção da doença e recuperar a autoestima.A segunda compõe-se dos seguintes temas individuais: descuidado quanto à doença e descuido quanto ao corpo.

Exemplificando a categoria percebendo e conhecendo a afecção dermatológica, descrevem-se as falas dos membros do grupo pesquisador:

Hoje eu me vejo muito feliz por saber o que eu tenho e saber que com muito cuidado com a pele eu vou sempre viver bem e muito melhor. Como uma grande guerreira, lutadora, vencedora. Pois apesar de estar com uma doença que me restringe a muitas coisas, consigo cuidar dos três bens maiores e fortalezas que tenho meus filhos. (Grupo-Pesquisador) 
Os copesquisadores relataram como percebem em seu corpo e nas relações sociais as mudanças causadas pela doença. Porém demonstra como o conhecimento acerca da doença foi importante para percebê-la e, assim, se tratar melhor. Por mais que cause limitações físicas e/ou sociais, o sujeito deve se permitir lutar pelos seus objetivos, buscar a convivência com a família e em seu meio social.

Conhecendo a doença, ou seja, descobrindo a fisiopatologia da doença de pele, muitas vezes associada na mente popular, à ideia de contágio e pouco asseio pessoal, já que tal mito pode levar ao afastamento do convívio com outros indivíduos em relação aos acometidos dessas doenças ${ }^{(22)}$. Para tanto, conhecer a semiologia e semiotécnica voltada aos cuidados com a pele requer uma atenção voltada para a pessoa acometida por uma doença que emite seus sinais visíveis na pele, deve-se valorizar a sensibilidade, o diálogo e as suas expressões ${ }^{(23)}$.

Quanto à categoria descuido consciente com o corpo,_descrevem-se as falas dos membros do grupo pesquisador:

[...] sou manicure mais não tenho cuidado de mim, meus cabelos eram lindos e longos.

Sinto-me relaxada...

[...] como estou agora, gorda e relaxada comigo mesma sem ânimo e vontade de viver. (Grupo-Pesquisador)

Os copesquisadores relatam que apesar de saberem da importância de se cuidar, informam que não se cuidam, ou seja, se transforma em um descuido consciente. Descuido este que pode ser justificado pelo caráter da doença de pele, que compromete a autoimagem levando a uma baixa autoestima. Assim, os indivíduos com baixa autoestima experimentam provavelmente mais efeito negativo quando se pensa em si e, consequentemente, podem ser motivados para suprimir pensamentos relacionados com o self ${ }^{(24)}$.

\section{CONCLUSÃO}

Conclui-se que, a sociopoética como uma construção coletiva revelou-se, nesta pesquisa, como uma importante ferramenta tanto no cuidar/educar/pesquisar em enfermagem como na abordagem humanista aos clientes com afecções dermatológicas.

Contanto, o presente estudo traz como contribuição uma perspectiva de cuidar em enfermagem que atenda às necessidades humanas, em especial às pessoas com alterações de autoimagem, propondo na área de enfermagem em dermatologia, um cuidado abrangente ás dimensões corporais, enfocando nas possibilidades e limites do cuidado terapêutico à pele, invólucro da mente e espírito do ser humano.

Porque através dela pode-se, inclusive, diagnosticar necessidades junto aos clientes tais como: compreender as suas limitações; ajudá-los a realizar as suas escolhas e a tomar decisões; estabelecer uma comunicação terapêutica; possibilitar a expressão dos sentimentos; ser paciente com o cliente; preservar a autoestima e autoimagem do profissional e cliente; manter uma relação de atenção, confiança, amor e carinho; atentar para as necessidades de hidratação, alimentação, higiene corporal, de lazer.

Sendo assim, ao analisar a dimensão imaginativa referente à convivência das pessoas com a enfermidade citada, este recorte de dissertação de mestrado contribuiu para uma ampliação da perspectiva da imagem e estima das mesmas, na tentativa de possibilitar o desenvolvimento do cuidado de enfermagem cada vez mais próximo ao cliente por meio da interação e do diálogo. 


\section{REFERÊNCIAS}

I.Chibante CLP,Santos FHE, Santos TD. Perfil de clientes hospitalizados com lesões cutâneas. Perfil de clientes hospitalizados com lesões cutâneas. Rev Cubana Enferm. [Internet] 2015 [acesso em I I Ago 2020]; 3 I (4). Disponível em: http://www. revenfermeria.sld.cu/index.php/enf/article/view/895//36

2.Araújo STC, Cunha LP, Azevedo AL, Almeida LP, Barcellos AMC, Valadares GV, Silva PS. (2020). Corpo e sociopoética: reflexões sobre os sentidos sociocomunicantes para enfermagem hospitalar. Research, Society and Development [online] 2020 [acesso em 4 ago 2020]; v. 9, n. 8, e729986I67. doi: http://dx.doi.org/ l 0.33448/rsd-v9i8.6 I67

3.Freire P. Pedagogia do oprimido. 50. ed. São Paulo: Paz e Terra; 20II.

4.Lourau R. René Lourau na UERJ: análise institucional e práticas de pesquisa. Rio de Janeiro: UERJ, 1993.

5.Deleuze G, Guattari F. Mil platôs: capitalismo e esquizofrenia v. I. São Paulo: Ed. 34, 2004.

6.Barbier R.A pesquisa-ação. Brasília, DF: Plano; 2002.

7.Boal A. Jogos para atores e não-atores. 2. ed. Rio de Janeiro: Civilização Brasileira; 1999.

8. Gauthier J. Sociopoética e formação do pesquisador integral. Revista Psicologia, Diversidade e Saúde, Salvador [Internet] 2015 [acesso em 3I Jul 2020];4(I):78-86. Disponível em: https://www5.bahiana.edu.br/index.php/psicologia/article/ view/459/526

9. Elias ADS, Oliveira FA, Tavares CMM, Muniz MP, Abrahão AL, Silva LSAH. Sociopoética: laços entre arte e educação. Revista PróUniverSUS [Internet] 2016 [acesso em 31 Jul 2020]; jan./jun.; 07 (2): 39-42. Disponível em: http://editora.universidadedevassouras.edu.br/index.php/RPU/article/view/350

10.Veronese M, Ferrarini A. A pesquisa sociopoética nas Ciências Sociais. Estud. sociol. Araraquara [Internet] 2016 [acesso em I I Ago 2020]; v.2 I n.4 I p.4 I I-428 jul.-dez. Disponível em: https://periodicos.fclar.unesp.br/estudos/article/view/8073/6067

I I. Santos I. dos. Sociopoética: uma ponte para o cuidar / pesquisar em enfermagem. Index Enferm., Granada. [Internet] 2005 [acesso em I I Ago 2020];v. 50. Disponível em: http:// www.index-f.com/index-enfermeria/50revista/p5233.php

12. Lopes WMPS, Figueiredo MLF. O cuidado transcultural como base para investigar idosas mastectomizadas sobre o conhecimento e o uso de sutiãs e próteses externas. Enferm. Foco [Internet] 20II [acesso em II Ago 2020]; 2(supl):8I-84. Disponível em: http://revista.cofen.gov.br/index.php/enfermagem/article/view/88

13. Santos FB, Valente GSC. Sistematização da Assistência de Enfermagem e a Segurança do Paciente no ambiente domiciliar. Enferm. Foco [Internet] 2020 [acesso em 05 Ago 2020]; I I (I): I06-I I 3. Disponível em: http://revista.cofen. gov.br/index.php/enfermagem/article/view/2679/7/ 3

14. Santos I dos et al. $\bigcirc$ grupo pesquisador construindo ações de autocuidado para o envelhecimento saudável. Esc. Anna Nery Rev. Enferm. Rio de Janeiro. [Internet] 2012 [acesso em 26 Out 2020]; v. I5, n. 4, p. 746-754, out./dez. Disponível em: https://www.scielo.br/scielo.php?script=sci_arttext\&pid=S I | |4-8 | 4520 I I0004000 I 3

I5. Moser G, Aguiar D, Gelbcke F, Schoeller S, Castro F, Maier S, Sudré G. O cuidado em saúde no ambiente hospitalar: interferência na reabilitação da pessoa com lesão medular. REAID [Internet]. 3 I ago.2020 [acesso em 26 Out 2020];93(3I):e-20032. Disponível em: https://revistaenfermagematual.com.br/index.php/revista/article/view/76I

16. Santos I dos et al. Cuidar da integralidade do ser: um desafio no domínio da enfermagem. Rev. Enferm. UERJ, Rio de Janeiro. [Internet] 2012 [acesso em 26 Out 2020]; v. 20, n. I, p. 4-9, jan./mar. Disponível em: https://www.e-publicacoes. uerj.br/index.php/enfermagemuerj/article/view/3967

17. Lima ACS et. al. Os Efeitos de Fatores Psicossomáticos no Tecido Cutâneo: Uma Revisão de Literatura. Revista Científica Multidisciplinar Núcleo do Conhecimento [Internet] 2018 [acesso em 05 Ago 2020]; ano 03, ed. 06, v. 03, p. 32-5I, junho. Disponível em: https://www.nucleodoconhecimento. com.br/saude/fatores-psicossomaticos

18. Melo K, Dourado Gonçalves F, da Silva W, Soares A, da Silva C,Araújo Sousa F, Natasha Lima Cruz M, de Andrade Rodrigues Severo E, Pereira Sousa Filho C, Sousa B, Costa Miranda L. A percepção do paciente amputado diante da mudança na imagem corporal. REAID [Internet] 2020 [acesso em 24 Out 2020];93(3I): e-20025. Disponível em: https://revistaenfermagematual.com.br/index.php/revista/article/view/70 I

19. Lupi O, Boleira M. Dermatologia fundamental. Rio de Janeiro: Guanabara Koogan; 2013.

20. Monbourquette J. Da autoestima à individuação: psicologia e espiritualidade. São Paulo: Paulinas; 2008.

21. Rocha RCNP, Pereira ER, Silva RMCRA. A dimensão espiritual e sentido da vida na prática do cuidado de enfermagem: enfoque fenomenológico. REME- Rev Min Enferm. [Internet] 20I8[acessi em 26 Out 2020];22:e-I I 5 I. Disponível em: http://reme.org.br/artigo/detalhes/I 294

22. Hoffmann et al.A integração mente e corpo em Psicodermatologia. Psicol.Teor. prát., São Paulo. [Internet] 2005 [acesso em 26 Out 2020]; v. 7, n. I, p. 5I-60. Disponível em: http://editorarevistas.mackenzie.br/index.php/ptp/article/view/ 1026/743

23. Santos I, Brandão ES, Clos AC. Enfermagem Dermatológica: competências e tecnologia da escuta sensível para atuar nos cuidados com a pele. Rev. enferm. UERJ, Rio de Janeiro. [Internet] 2009 [acesso em 26 Out 2020]; jan/mar; I7(I):124-9. Disponível em: http://files.bvs.br/upload/S/0 I04-3552/2009/vI7n l/a022.pdf

24. Castro NB, Lopes MVO, Monteiro ARM. Baixa Autoestima Crônica e Baixa Autoestima Situacional: uma revisão de literatura. Rev Bras Enferm. [Internet] 2020 [acesso em 26 Out 2020];73(I):e20 I80004. Disponível em: https://www.scielo.br/ pdf/reben/v73nI/pt_0034-7I67-reben-73-0 I-e20 I80004.pdf

Recebido: $2020-08-25$

Aceito: 2020-12-04 